\title{
INTERNACIONALIZAÇÃO DE EMPRESAS BRASILEIRAS E O PAPEL DA INOVAÇÃO NA CONSTRUÇÃO DE VANTAGENS COMPETITIVAS
}

\author{
Eva Stal \\ Doutora em Administração pela Universidade de São Paulo - USP \\ Professora da Universidade Nove de Julho - PMDA/UNINOVE \\ estal@uninove.br
}

\section{RESUMO}

Muitas empresas de países emergentes temem explorar mercados internacionais por causa da distância entre as empresas globais e os padrões tecnológicos locais. Em geral, buscam o desenvolvimento tecnológico mediante a cópia, adaptação e melhoria de soluções alheias, porém um número crescente de empresas vem se destacando no cenário global, com a inovação de produtos e serviços para o mercado externo. A internacionalização por meio do investimento externo pode ser a única alternativa para empresas que enfrentam a competição global, e o sucesso de sua inserção externa dependerá, cada vez mais, da criação de vantagens competitivas baseadas em inovações tecnológicas. $\mathrm{O}$ trabalho descreve as motivações e a trajetória de internacionalização de cinco empresas nacionais de diferentes setores industriais - Sabó (autopeças), Natura (higiene e cosméticos), Totvs (software), Embraer (aviões), e Marcopolo (carrocerias de ônibus) -, destacando o papel da inovação tecnológica na sua competitividade internacional.

Palavras-chave: Inovação tecnológica; Países emergentes; Internacionalização; Competitividade. 


\section{INTRODUÇÃO}

Países emergentes buscam o desenvolvimento tecnológico com atraso, na maior parte das vezes copiando e adaptando soluções exógenas. Porém, já existe um número significativo de empresas desses países que se destacam no mercado global, como resultado de estratégias em que a inovação tecnológica tem papel relevante. O esforço inovador é sempre recompensado, mas é muito mais difícil em países nos quais a infraestrutura de pesquisa em universidades, institutos e nas próprias empresas é mais modesta. Ou seja, os sistemas nacionais de inovação (Nelson, 2006) não estão plenamente desenvolvidos, dificultando as interações entre as diferentes instituições que determinam o desempenho inovador das empresas nacionais.

No caso brasileiro, o conteúdo tecnológico dos produtos exportados ainda é baixo. Nos últimos anos, os esforços do governo para a criação de leis e programas de estímulo e apoio à inovação nas empresas - Lei de Inovação, Lei do Bem, Subvenção Econômica, Juro Zero, entre outros influenciaram a pauta das exportações brasileiras. Mas os bens intensivos em tecnologia ainda são uma proporção muito pequena do total, tendo passado de 1,06\% em 1996 para 4,2\% em 2008. Para a Associação de Comércio Exterior do Brasil (AEB), as commodities ainda respondem por 65\% da pauta de exportações. Os escassos $35 \%$ ocupados pelos produtos manufaturados devem-se à falta de tecnologia própria $-72 \%$ das exportações desses produtos são feitas por subsidiárias de multinacionais estrangeiras. A comparação com China e Índia é desproporcional - o porcentual de manufaturados nas exportações desses países é, respectivamente, de $93 \%$ e $80 \%$ (Castro, 2009).

Além das exportações de commodities, em que o Brasil é muito competitivo, é preciso concorrer com produtos mais sofisticados, cujos preços internacionais são bem mais elevados. Por outro lado, a busca de condições financeiras mais vantajosas, as barreiras protecionistas impostas aos produtos brasileiros, e a necessidade de reduzir custos de transporte e logística são fatores de estímulo à internacionalização, por meio do investimento direto no exterior. A produção fora do país estimula as exportações de matérias-primas e componentes, e é a estratégia clássica de vencer barreiras tarifárias e não tarifárias, sobretudo em setores industriais de bens de maior conteúdo tecnológico (Arbix, Salerno, $\&$ De Negri, 2005). Também é uma forma de buscar melhorias tecnológicas, que ajudam a conquistar a liderança no mercado local. Empresas transnacionais concentram 65\% do comércio exterior, mais de $80 \%$ das inovações e $90 \%$ dos investimentos mundiais, logo a melhor estratégia para vencê-las é ter uma atuação mais abrangente, envolvendo exportação, distribuição, marketing e instalação de unidades produtivas no exterior (Lacerda, 2004).

Revista de Administração e Inovação, São Paulo, v. 7, n. 3, p. 120-149, jul./set. 2010 
Este trabalho descreve as motivações e a trajetória de internacionalização de cinco empresas nacionais de diferentes setores industriais - Sabó (autopeças), Natura (higiene e cosméticos), Totvs (software), Embraer (aviões) e Marcopolo (carrocerias de ônibus). Ele mostra em que medida a inovação tecnológica contribuiu para as vantagens competitivas que permitiram a essas firmas se destacar no mercado global.

\section{REFERENCIAL TEÓRICO}

\subsection{INOVAÇÃO TECNOLÓGICA, COMPETITIVIDADE E INTERNACIONALIZAÇÃO}

Empresas multinacionais de países emergentes vêm se destacando no mercado global, mediante investimentos diretos. Países como Coreia do Sul, Malásia e Cingapura iniciaram essa trajetória na década de 1980, foram seguidos por Chile, México e África do Sul, e, mais recentemente, Brasil, China e Índia (United Nations Conference on Trade and Development [UNCTAD], 2004).

A internacionalização é uma alternativa para o crescimento das empresas, permitindo sua exposição a padrões internacionais de produtos, tecnologias e métodos de gestão, gerando importantes retornos para as operações domésticas. Ao aumentar o tamanho do seu mercado, permite que a empresa invista mais em P\&D, pela maior facilidade de retorno. Investimentos em países desenvolvidos trazem grandes vantagens, seja na compra de uma firma existente, em que se garante o acesso à base de experiência, habilidades e conhecimento tecnológico, seja na instalação de uma nova fábrica, especialmente em locais com grande concentração de empresas de alta tecnologia ou de fornecedores locais (Chudnovsky \& Lopez, 2000).

Os desafios da internacionalização são grandes, mas existem muitos fatores de motivação, como o desejo de crescer e buscar novas oportunidades; marcar presença no mercado global, colocando-se próxima aos clientes; buscar economia de escala para reduzir custos; e a necessidade de competir e de estar entre os líderes do mercado. Rocha (2001) apresenta alguns argumentos para justificar a não internacionalização das empresas brasileiras, entre os quais o isolamento geográfico, que favorece apenas o contato com os nossos parceiros do Mercosul. A barreira do idioma é significativa, ao lado da distância psicológica.

Empresas brasileiras têm tradição em exportação de produtos, mas pouca em exportação de capital, com investimentos diretos no exterior. Iglesias e Veiga (2002) mostraram como era pequeno o grau de internacionalização produtiva das empresas de capital nacional, quando comparados com os de 
empresas coreanas ou de outros países do sudeste asiático, ou até com alguns países latino-americanos: apenas $20 \%$ de uma ampla amostra de exportadores brasileiros, em sua maioria de capital nacional, possuíam à época investimentos no exterior, concentrados nos Estados Unidos e na Argentina; 85\% referiam-se a atividades comerciais e de distribuição de produtos, e somente $12 \%$ referiam-se à produção. Além disso, $40 \%$ das firmas não tinham intenção de investir no exterior.

Poucos trabalhos focalizam o papel da tecnologia no esforço de internacionalização. Tigre (2002) aborda a questão da política tecnológica na promoção das exportações e as etapas na internacionalização das empresas, mediante um levantamento com 460 empresas exportadoras de 18 setores econômicos. Para as empresas líderes desses setores, o aumento das operações externas, o desenvolvimento tecnológico e a eficiência competitiva em mercados regionais e globais constituíam estratégias imprescindíveis, caso contrário sua sobrevivência, a longo prazo, estaria ameaçada. Para o autor, o apoio à internacionalização das grandes empresas nacionais seria fundamental, não apenas para viabilizar as exportações, mas para manter a capacidade futura de enfrentar a concorrência de grandes grupos internacionais.

Arbix et al. (2005) procuraram identificar as características de empresas industriais que se internacionalizam com foco na inovação tecnológica, visando subsidiar ações governamentais. Utilizando grandes bases de dados nacionais, o trabalho mostra que tais empresas remuneram melhor a mão de obra, empregam funcionários com maior escolaridade, e investem um porcentual maior em treinamento, em relação ao faturamento, o que aumenta a qualificação da mão de obra doméstica. Empresas inovadoras têm $16 \%$ mais chances de sucesso na exportação e conseguem cobrar preços maiores por seus produtos.

Entretanto, as empresas brasileiras, e também as latino-americanas, são globalmente competitivas em produtos de consumo intermediário, fortemente baseados em recursos naturais, não se destacando nos setores mais dinâmicos e inovadores do comércio internacional (Tavares \& Ferraz, 2007).

As empresas podem tornar-se internacionais mediante fusões e aquisições, porém a maioria deve sua inserção nos mercados mundiais a produtos inovadores, o que constitui uma das dificuldades sentidas pelas empresas brasileiras (Ghoshal \& Tanure, 2004).

O investimento direto estrangeiro (IDE) teve um papel relevante no processo de transformação econômica e crescimento de muitos países emergentes nas duas últimas décadas. A entrada de capitais, tecnologia e capacidade gerencial dos países industrializados beneficiou os mercados emergentes de tal modo que, em curto período de tempo, algumas empresas acumularam capital e conhecimento, o que lhes permitiu investir no exterior, tornando-se multinacionais emergentes (Narula \& Zanfei, 2005). 
A noção de inovação e sua importância para o desenvolvimento econômico dos países foram reconhecidas primeiramente pelo economista Joseph Schumpeter, durante a década de 1930, que identificou cinco tipos de inovação: novos produtos ou mudanças substanciais em produtos existentes (inovação tecnológica de produto); novos processos ou métodos de produção (inovação tecnológica de processo); novos mercados; novas fontes de recursos; e novas organizações (Schumpeter, 1985). Vista como tal, a inovação vai além de questões tecnológicas, incluindo também o atendimento das necessidades dos clientes.

Foi só a partir dos trabalhos de Schumpeter que a tecnologia passou a ser analisada mais profundamente nas teorias de desenvolvimento econômico. $\mathrm{O}$ autor concentrou sua atenção nos efeitos positivos das inovações no desenvolvimento econômico, analisando também o papel da empresa e dos empreendedores no processo.

A inovação tecnológica também pode ser considerada peça-chave na obtenção da competitividade de um país. Porter (1993) aborda a necessidade de uma nova teoria sobre vantagem competitiva, em que a inovação e o melhoramento em métodos e tecnologia são os elementos centrais. Ele afirma também que a base da vantagem competitiva de um país está em sua capacidade de criar um ambiente de estímulo à inovação.

A vantagem competitiva pode resultar do tamanho ou da posse de ativos pelas empresas, porém, cada vez mais, ela vem sendo relacionada à capacidade das empresas em mobilizar conhecimento, habilidades tecnológicas e experiência para elaborar novos produtos e serviços, e novas formas de entregá-los (Tidd, Bessant, \& Pavitt, 2005).

O modelo de estratégia da Visão Baseada em Recursos (VBR) considera que as empresas possuem recursos e capacidades, em que recursos são os ativos tangíveis e intangíveis que a empresa controla e que são usados para definir e implantar estratégias (Barney, 1991). As combinações dos recursos tangíveis e intangíveis resultam nas capacidades que permitem à empresa organizar, coordenar e maximizar o aproveitamento dos recursos, conseguindo uma vantagem competitiva sustentável. As empresas possuem conjuntos diferentes de recursos e capacidades, mesmo que concorram no mesmo setor, o que torna umas mais competentes do que outras. Alguns recursos são críticos, e não se pode comprar, imitar ou substituir, pois são conhecimentos acumulados em um processo de aprendizagem interno às empresas.

Aquisições internacionais ajudam a empresa a obter conhecimento e tecnologia, mas para sustentar uma vantagem competitiva ao longo do tempo são necessárias capacidades dinâmicas para integrar, construir e reconfigurar as competências externas e internas da empresa, de modo a combinálas e responder adequadamente às mudanças do ambiente e exigências dos consumidores, 
desenvolvendo novos produtos, processos e serviços e gerando vantagens competitivas sustentáveis (Teece, Pisano, \& Shuen, 1997). Minda (2008) cita autores que abordam a influência das capacidades tecnológicas sobre o processo de globalização de empresas de países emergentes.

\subsection{TIPOLOGIAS DE ESTRATÉGIAS TECNOLÓGICAS EMPRESARIAIS}

A inovação tem um papel extremamente relevante nas estratégias competitivas das empresas, tendo Christopher Freeman apresentado, em 1974, uma classificação das estratégias tecnológicas, de acordo com o grau de investimento em atividades de $\mathrm{P} \& \mathrm{D}$, mas também as relacionando à importância que a empresa dedica à inovação, mediante processos deliberados e sistemáticos (Freeman \& Soete, 2008). Embora reconheçam a arbitrariedade de tal agrupamento, as estratégias tecnológicas foram distribuídas em seis grupos, para efeito de conceituação: ofensiva, defensiva, imitativa, dependente, oportunista e tradicional. Na prática, existem diversas possibilidades de gradação entre esses tipos. E uma empresa pode adotar diferentes estratégias tecnológicas em períodos distintos.

A diferenciação de produtos exige intensa atividade de $\mathrm{P} \& \mathrm{D}$, ações de inteligência competitiva/ inteligência tecnológica, colaboração com universidades e institutos de pesquisa, proteção de patentes e recursos humanos qualificados, configurando uma estratégia tecnológica ofensiva, cujo objetivo é alcançar a liderança técnica e de mercado, antecipando-se aos concorrentes na introdução de novos produtos.

A estratégia tecnológica defensiva também envolve esforços de inovação sistemáticos e constante desenvolvimento de produtos. Mas as empresas que a adotam não querem correr o risco de serem as primeiras, preferindo esperar que seus concorrentes façam isso, aprendendo com os seus erros e aproveitando a entrada em um novo mercado com soluções mais seguras (Tigre, 2006). Tais empresas são intensivas em conhecimento e empregam uma alta proporção de pessoal científico e técnico.

Empresas que adotam uma estratégia imitativa se contentam em acompanhar as líderes das tecnologias estabelecidas. A firma imitadora precisa usufruir certas vantagens para entrar num mercado em competição com firmas inovadoras já estabelecidas, como proteção de mercado ou outros privilégios como isenção de impostos; caso contrário, será necessário contar com baixos custos de mão de obra e outros insumos. Um exemplo de adoção dessa estratégia por parte das empresas ocorreu no Brasil, nos anos 1970 e 1980, quando vigorou a política de substituição de importações.

A empresa que utiliza uma estratégia dependente aceita um papel de subordinação a outras firmas. Ela não toma a iniciativa de inovar, atuando em resposta a exigência de clientes ou 
controladores, e depende de instruções técnicas fornecidas pelas empresas demandantes da inovação. Exemplos são as empresas que fabricam produtos que são vendidos com outras marcas, numa terceirização da produção, ou as franquias (Tigre, 2006).

Os produtos de empresas que adotam uma estratégia tradicional mudam muito pouco. Elas não veem razão para mudanças, ou porque o mercado não exige, ou porque não se sentem ameaçadas pelos concorrentes. Em geral, sua tecnologia se baseia em habilidades técnicas de seus funcionários. Finalmente, a estratégia oportunista, também chamada de estratégia de nicho, é caracterizada pela percepção de uma nova oportunidade num mercado em rápida mudança, sem grande investimento em P\&D. Consiste no fornecimento de um produto ou serviço que os consumidores desejam ou de que necessitam, mas que ninguém ainda havia pensado em oferecer (Freeman \& Soete, 2008).

\subsection{PRINCIPAIS TEORIAS SOBRE O PROCESSO DE INTERNACIONALIZAÇÃO DE EMPRESAS}

Dentre as várias teorias que explicam a internacionalização de empresas, duas se destacam especialmente - o paradigma eclético da produção internacional ou paradigma OLI, no âmbito das teorias econômicas (Dunning, 1988, 2001), e a Escola de Uppsala, entre as teorias comportamentais (Johanson \& Vahlne, 1977). A primeira afirma que as empresas precisam ter vantagens de propriedade (O - ownership), ou seja, recursos que as tornem competitivas no mercado internacional, entre os quais destacam-se o conhecimento e a tecnologia; devem existir vantagens de localização ( $\mathrm{L}$ - location) nos diferentes países, que atraiam as empresas para lá se instalarem; e, uma vez ponderados esses fatores, as empresas decidem se é melhor internalizar (I - internalization) a produção naqueles países ou se é melhor exportar seus produtos ou licenciar sua produção para uma firma local. A entrada em um novo país pode ocorrer mediante a instalação de escritórios comerciais, em geral para melhor coordenar as exportações do país de origem, ou pela instalação de fábricas, próprias ou em parceria com empresas locais. A entrada de empresas de países emergentes por meio da aquisição de firmas em países desenvolvidos é uma estratégia que visa, principalmente, obter o conhecimento, a tecnologia e os canais de distribuição da empresa adquirida.

Para a Escola de Uppsala, as empresas se expandem para países nos quais a distância psicológica seja menor, com cultura e ambiente similares. Este é um processo incremental e, à medida que cresce o conhecimento sobre esses países, as empresas aumentam seus investimentos locais, em uma cadeia de estabelecimento, sob a forma de escritórios comerciais, lojas e fábricas.

Revista de Administração e Inovação, São Paulo, v. 7, n. 3, p. 120-149, jul./set. 2010 
Segundo Dunning (1994), as empresas se internacionalizam motivadas pela busca de um ou mais fatores: recursos naturais (resource seeking), mercado (market seeking), eficiência produtiva (efficiency seeking), e ativos estratégicos (strategic asset seeking). Empresas que utilizam estratégias do tipo resource seeking buscam explorar as vantagens derivadas de recursos naturais a custos comparativamente menores nos países-alvo. Estratégias do tipo market seeking buscam, a partir de um dado país-alvo, explorar as vantagens de mercados vizinhos. Multinacionais cuja motivação é efficiency seeking buscam explorar as vantagens de escala e racionalização da produção, especialização, processos de integração regional entre filiais, redução de custos de transporte e avanços de infraestrutura. No caso de strategic asset seeking, a empresa busca um conjunto de competências (entre as quais a inovação de produtos e canais de distribuição) que proporcione a ela vantagem competitiva naqueles mercados.

A partir de 1990, a liberalização econômica na América Latina obrigou as empresas locais a aprimorar produtos e processos de fabricação para competir com as firmas estrangeiras nos mercados globais. Ela teve papel fundamental no estímulo à internacionalização, ao modificar as condições ambientais em que as empresas atuavam, exigindo aumento de competitividade. Empresas estatais, que haviam crescido e se consolidado sob a proteção governamental, foram privatizadas, em condições competitivas para concorrer no exterior. Não foram necessárias políticas públicas de apoio à internacionalização - a simples remoção de barreiras institucionais impulsionou as empresas a buscar novos mercados.

A decisão de produzir no exterior, em vez de licenciar ou exportar, é fortemente influenciada pela natureza dos ativos intangíveis, que resultam das práticas tecnológicas, de gestão ou de comercialização da empresa. Entre eles, destaca-se o conhecimento implícito, que a firma pode usar, mas não pode vender nem licenciar, razão pela qual esses ativos estimulam o investimento na produção internacional.

Em indústrias nas quais os ativos proprietários intangíveis sejam importantes, encontra-se um grande número de firmas multinacionais. No entanto, firmas sem vantagens proprietárias sofisticadas permanecerão na etapa exportadora ou, no máximo, realizarão alguns investimentos externos para melhor comercializar a produção doméstica (Dunning, 1988). Produzir no exterior exige vantagens de propriedade significativas, para vencer os custos de transação. Este é o caso das empresas estudadas neste artigo. 


\section{METODOLOGIA}

Selecionamos, por conveniência, um conjunto de empresas brasileiras de diferentes setores, com atividades constantes de inovação tecnológica, com áreas de $\mathrm{P} \& \mathrm{D}$ formais, e que se internacionalizaram, mediante a abertura de fábricas (Sabó, Marcopolo, Embraer), centros de assistência técnica (Embraer e Marcopolo), lojas próprias (Natura e Totvs) ou franquias (Totvs). E buscamos verificar se a inovação tecnológica teve contribuição relevante para o sucesso no mercado internacional.

Foi utilizada a abordagem qualitativa, com níveis de pesquisa exploratória e descritiva. No primeiro nível, procuramos descobrir variáveis significativas na situação real (Festinger\& Katz, 1966), que sustentam a história e a trajetória internacional das empresas, considerando que ainda há pouco conhecimento acumulado e sistematizado no Brasil sobre a internacionalização de empresas, com enfoque na capacidade tecnológica. No segundo nível, buscou-se o estabelecimento de relações entre variáveis (Gil, 2002). Algumas pesquisas descritivas vão além, pretendendo determinar a natureza dessa relação, caso em que elas se aproximam da pesquisa explicativa. Porém, em geral, os estudos de caso não dão respaldo a esse nível de pesquisa. Eles podem ser, ao mesmo tempo, exploratórios e descritivos. Estudos de caso múltiplos podem ser explicativos de determinado fenômeno, caso ele ocorra nos vários casos estudados.

O método de pesquisa empregado foi o estudo de casos múltiplos. Como técnica de coleta de dados, utilizamos pesquisa bibliográfica da literatura acadêmica; reportagens sobre as empresas na mídia (EXAME, Gazeta Mercantil, Valor Econômico); livros de negócios que relatam experiências de empresas; e pesquisa documental em sites das empresas na Internet. Dados primários foram obtidos através de entrevistas nas empresas, com os responsáveis pela área de P\&D ou pela área de gestão internacional. O roteiro de entrevista incluiu questões sobre as etapas do processo de internacionalização da empresa, posição competitiva no Brasil e nos vários países, estratégia empresarial e tecnológica, alianças estratégicas, capacitação tecnológica e transferência de tecnologia. O modelo conceitual da pesquisa é apresentado abaixo. 
Figura 1 - Modelo conceitual da pesquisa

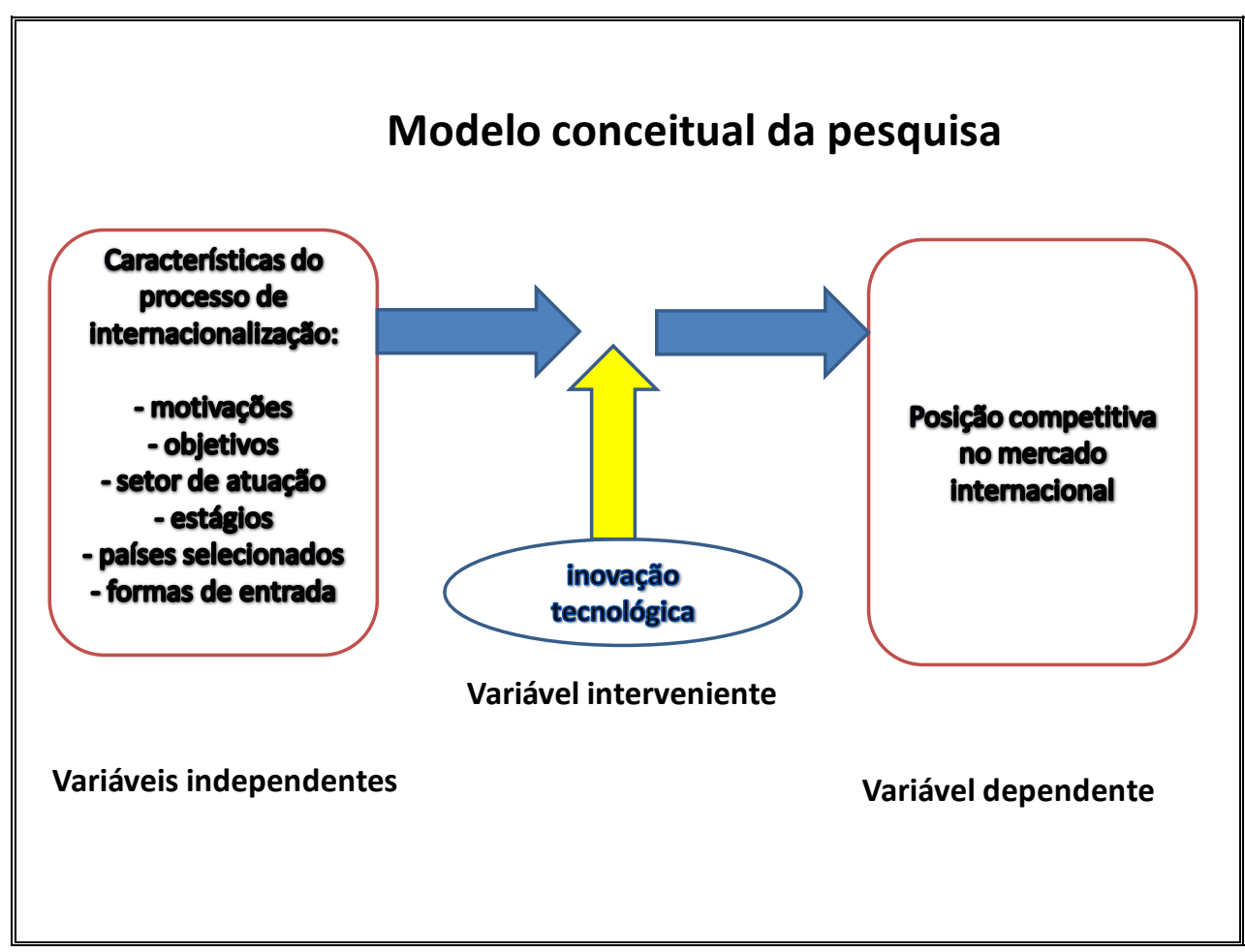

Fonte: Elaborado pela autora

\section{APRESENTAÇÃO DE RESULTADOS - ESTUDOS DE CASO}

\subsection{SABÓ INDÚSTRIA E COMÉRCIO LTDA}

A Sabó é a terceira maior fornecedora de sistemas de vedação para a indústria automobilística mundial e a maior fabricante nacional de autopeças, com $80 \%$ do mercado nacional de retentores, além de exportar para cerca de 80 países, e entre seus clientes estão as grandes montadoras. Na década de 1980, as vendas no mercado externo representavam $8 \%$ do faturamento, chegando a $60 \%$ em 2008 , somando as receitas das fábricas e as exportações.

Foi fundada em 1942 por dois imigrantes, como uma pequena fábrica de peças de reposição para automóveis, aproveitando as dificuldades de importação durante a Segunda Guerra. Em 1944, fabricou o primeiro retentor, a pedido de um cliente (Levy, 2002). A preocupação com tecnologia levou a empresa a tomar uma importante decisão estratégica, em 1962 - a de investir em laboratório próprio de P\&D. Em 1966, inaugurou a Fábrica de Juntas Flexa e, em 1973, a Famapre, de máquinas. Nesse ano, ganhou o prêmio de qualidade atribuído por uma montadora. Em 1975, começou a fornecer retentores 
para a OPEL e licenciou tecnologia de produto para a alemã Bruss. Em 1978 inaugurou a fábrica de mangueiras Senaflex, completando o grupo de produtos - retentores, juntas e mangueiras.

A Sabó cresceu ininterruptamente desde a sua criação. Após a abertura econômica, em 1990, foi a única empresa de autopeças que permaneceu nacional, enquanto Metal Leve, Cofap, Varga, Braseixos e Nakata passaram ao controle estrangeiro (Sull \& Escobari, 2004). A Sabó realizou o caminho inverso - internacionalizou-se, comprando empresas no exterior e se firmando no mercado internacional. Desde o início desse processo, em 1992, ela definiu que só abriria fábricas em mercados onde tivesse contratos garantidos. Naquele ano, adquiriu duas plantas de retentores na Argentina. Foi uma decisão estratégica e, ao mesmo tempo, de sobrevivência, ao decidir atuar diretamente nos países que abrigavam a sede de seus concorrentes, estando próxima dos centros de desenvolvimento de seus clientes, as montadoras. Na época, parecia não haver alternativa, pois novas montadoras chegavam ao Brasil com fornecedores alinhados mundialmente. A grande oportunidade veio em 1993, quando a Sabó comprou a concordatária Kaco. Com três fábricas na Alemanha e uma na Áustria, a Kaco já era a segunda maior fabricante alemã de retentores, o principal produto da Sabó. Isso representou a certeza de continuar como fornecedora preferencial da Opel (Ferraz, 2002).

Em 1997, foi construída uma nova fábrica na Hungria, acompanhando a Audi, e em dois anos a Sabó duplicou sua capacidade de produção para atender ao mercado europeu. O ano de 1998 marcou o início das vendas para as montadoras americanas. No Brasil, a empresa possui duas plantas, em São Paulo e em Mogi-Mirim. A segunda fábrica foi inaugurada em dezembro de 2005, dada a expectativa de vendas cada vez maior para os Estados Unidos, o que se confirmou, levando à instalação de fábrica naquele país, em 2007.

Além das fábricas, a empresa possui escritórios técnico/comerciais na França, Austrália, Itália, Inglaterra e no Japão. Neste país, o objetivo é aproximar-se da Toyota e da Honda, onde são definidos os projetos de novos veículos, bem como os fornecedores. Ainda em fase de prospecção, o escritório japonês já fechou seu primeiro contrato com uma montadora.

Se a Sabó não tivesse se internacionalizado, já teria sido vendida ou estaria fora do mercado. Com tecnologia de ponta, alcançou aos poucos a liderança do mercado brasileiro. Em termos de tecnologia, Kaco e Sabó se equiparavam e acabaram beneficiadas pela união. A Sabó estava atualizada tecnologicamente porque sempre investiu de 3\% a 5\% do faturamento em P\&D, e cerca de $30 \%$ das vendas, a cada ano, provêm de novos projetos com clientes. Um processo pioneiro internacionalmente, desenvolvido em parceria com uma universidade alemã, deu-lhe o Prêmio Finep de Inovação Tecnológica 2003 (Stal, 2005). Ampliar a clientela foi possível com o diferencial tecnológico no desenvolvimento de produtos, com cerca de 300 itens a cada ano, novos ou aperfeiçoados. Em 2007, a 
empresa possuía 102 patentes ativas - 47 da Sabó e 55 da Kaco - e dois diretores de Tecnologia, no Brasil e na Alemanha. Entre os muitos prêmios recebidos, destacam-se o de Fornecedor do Ano da Audi, da Opel (seis vezes) e da Fiat Brasil (cinco vezes). Também recebeu certificados de qualidade da Ford Brasil (15 vezes), da GM Brasil (27) e 14 da GM Europa.

A empresa também se apoia em fontes externas de inovação, como parte importante de sua estratégia de aumento da competitividade. Fornecedores, clientes, concorrentes, empresas de outros setores, universidades e centros de pesquisa (Unicamp, USP, UFSCar, MIT no exterior) constituem fontes importantes. Há contratos de intercâmbio de informações com outras empresas em áreas de ponta, como nanotecnologia, eletrônica, engenharia de materiais, tratamentos de superfícies e plasma (Ganem \& Santos, 2006).

A estratégia de inovação tecnológica é bem definida e formalizada. Para projetos específicos, detectados pela empresa ou demandados por clientes (montadoras), ela busca parcerias externas (Gomes \& Kruglianskas, 2005). Uma inovação organizacional importante foi introduzida na empresa em 1996. É o trabalho por células de gestão (equipes multifuncionais), em que cada célula é dedicada a um grupo de dez a 30 clientes, o que deu mais agilidade ao atendimento - o tempo decorrido entre o pedido de um cliente e a entrega de um protótipo, que era de 120 dias, agora leva um mês. O grande desafio é superar as diferenças culturais, fazendo com que as operações no Brasil e no exterior trabalhem de forma mais unificada, introduzindo conceitos de gestão utilizados aqui.

Ao final de 2008, a empresa possuía um quadro de 4.600 funcionários, sendo 1.300 no exterior. O faturamento no ano, de cerca de US\$ 300 milhões, foi inferior ao de 2007, em razão da crise mundial. Em outubro, foi inaugurada a oitava fábrica no exterior, na China, para fornecer peças para uma planta de transmissões automotivas da Volkswagen, transferida da Alemanha para aquele país. O investimento de US\$ 10 milhões foi subsidiado pelo governo chinês, que não exigiu um parceiro local, por tratar-se de produção de componentes.

Apesar da crise de 2008, com redução das vendas e da produção, a empresa pensa em entrar na Índia e na Rússia, seja comprando um fabricante local, seja fornecendo peças para uma montadora, em linha com a sua estratégia de seguir os clientes.

\subsection{NATURA}

A Indústria e Comércio de Cosméticos Natura Ltda. foi fundada em 1969, para vender produtos fabricados com substâncias naturais, a partir de fórmulas de cosméticos herdadas de um familiar. Em 1974 optou pela venda direta, por meio de vendedoras especializadas, em vez de franquear os 
produtos, por receio de prejudicar a qualidade do atendimento. No início, as Consultoras de Beleza foram recrutadas entre as próprias clientes, que passaram a vender os produtos sob comissão. É um processo que vai além do sistema de venda porta a porta, buscando uma relação de confiança e proximidade entre a revendedora e os clientes (Pommez, 2004).

Até 1990, a Natura foi beneficiada pela política de substituição de importações, que tornava os produtos importados caros e inacessíveis a grande parte da população. A abertura comercial trouxe concorrentes estrangeiros para o Brasil, e muitas empresas locais fecharam ou foram vendidas. A Natura prosperou, passando a investir pesadamente em programas de qualidade e tecnologia (Ghoshal \& Tanure, 2004). Em 1999, adquiriu a Flora Medicinal, tradicional fabricante de fitoterápicos, que possuía um acervo de pesquisas com mais de 280 plantas brasileiras e 300 produtos (Sull \& Escobari, 2004). Isso aumentou a capacidade de inovação da empresa, para poder enfrentar os concorrentes globais.

A Natura é a maior fabricante de cosméticos da América Latina e a única representante da região no grupo das gigantes mundiais do setor. Domina 20\% do mercado brasileiro de produtos de Higiene Pessoal, Perfumaria e Cosméticos, no qual 1.694 empresas movimentaram R\$ 21,65 bilhões em 2008, e as vendas diretas representaram 7,2\% em volume e 29,3\% em valor (Associação Brasileira da Indústria de Higiene Pessoal, Perfumaria e Cosméticos [ABIHPEC], 2008). Em 2005, pela primeira vez, superou a Avon.

A empresa tem 5.700 funcionários efetivos (1.300 no exterior), entre os quais 700 promotoras de vendas, responsáveis por 730 mil consultoras (vendedoras autônomas) no Brasil (são 850 mil no total), que atuam nos 4.500 municípios brasileiros. As vendas pela internet representam $40 \%$ do total mensal, chegando a quase $50 \%$ no mês de dezembro.

Em maio de 2004, foram vendidas na bolsa $25 \%$ das ações dos três principais acionistas. A partir daí, a empresa experimentou um forte crescimento, e o valor de mercado passou de 3,6 bilhões de reais para 11 bilhões, em maio de 2007. Grande parte desse crescimento se deve ao investimento na criação de uma nova plataforma tecnológica baseada no uso sustentável da biodiversidade brasileira, na internacionalização de seus negócios e em mudanças operacionais envolvendo fornecedores, parcerias com comunidades locais, ONGs, governos e o setor acadêmico (Ferro \& Bonacelli, 2006).

A empresa começou a se internacionalizar em 1982, exportando para o Chile, depois para Bolívia, Argentina e Peru, em 1988 (neste país a operação foi posteriormente desfeita), por meio de distribuidores locais. A partir de 1994, estabeleceu operações próprias, com a montagem de centros de distribuição e a formação de consultoras de vendas na Argentina, Chile, Peru e Portugal. A proximidade física e cultural foi decisiva para começar pela América Latina, mas o processo não foi 
exitoso, por falta de controle sobre as atividades locais de marketing, distribuição e relacionamento com revendedoras. Hoje ela possui operações próprias (Casa Natura) no México, Colômbia, Argentina, Chile, Peru e França. Em agosto de 2009, por causa da insegurança institucional, decidiu sair da Venezuela.

A loja em Paris foi inaugurada em abril de 2005, e este foi considerado o verdadeiro desafio do seu processo de internacionalização, pois ser uma empresa de um país emergente era um obstáculo à entrada em mercados sofisticados. Na loja são vendidos produtos da linha Ekos, elaborados a partir de plantas da floresta amazônica, com grande apelo de marketing.

A partir de 2007, os indicadores financeiros da empresa sofreram uma inflexão, por conta de seu crescimento, e o valor de mercado caiu 45\% em 2007. Mas ela manteve a liderança do setor, com $13,4 \%$ de participação, ante $7,5 \%$ da Avon.

O processo de internacionalização também contribuiu para o aumento de despesas, com a formação de equipes e adequação de produtos para entrada em novos países, a partir de 2005 México, Colômbia, Venezuela e França (Natura, 2007, 2008). O lucro líquido teve queda acentuada em 2008, juntamente com o índice de inovação ${ }^{1}$ - o número de produtos lançados passou de 225 , em 2006, para 118 em 2008. Esses resultados provocaram uma severa mudança estrutural na empresa, aliada à focalização em um número menor de produtos, com maior retorno comercial, e colocaram a Natura novamente em uma trajetória de aumento de vendas e lucros (Costa, 2009; Natura, 2007, 2008).

A criação de valor na Natura deve-se à construção permanente da marca e à qualidade das relações com os diversos stakeholders - consumidores, consultoras, colaboradores, fornecedores, acionistas e parceiros -, mas também à inovação.

O setor de cosméticos se caracteriza por uma necessidade contínua de lançamento de produtos, que dependem de novos insumos, como essências e ativos funcionais (Ferro \& Bonacelli, 2006). O ciclo de renovação de produtos leva de dois a três anos, e para se adequar a esse ritmo, a Natura investe cerca de $3 \%$ de sua receita líquida em P\&D. A empresa não produz os princípios ativos, absorvendo conhecimentos da comunidade científica, de fornecedores e concorrentes, e gerando opções tecnológicas que são avaliadas pelo grupo de $\mathrm{P} \& \mathrm{D}$ da empresa, a partir das quais se estabelecem projetos de desenvolvimento tecnológico. Além do laboratório central de P\&D instalado na sede da empresa, com 200 pesquisadores, foi criado um centro avançado de tecnologia em Paris, em

${ }^{1}$ Receita anual resultante de novos produtos lançados nos 24 meses anteriores, em relação à receita anual total. Revista de Administração e Inovação, São Paulo, v. 7, n. 3, p. 120-149, jul./set. 2010 
2006, para realizar estudos sobre a pele. Os pesquisadores da empresa monitoram permanentemente o ambiente externo.

A linha Ekos começou utilizando ingredientes da biodiversidade de uso já conhecido na produção de cosméticos. Dali para a frente, para sustentar a linha a médio e longo prazo, seria necessário descobrir, pesquisar e desenvolver ativos completamente novos. Este foi o objetivo do projeto Natura Campus, lançado em março de 2003, que visava estimular a formação de competência científica e tecnológica aplicada a cosméticos e fitoterápicos, mediante a montagem de uma rede entre pesquisadores e instituições. O programa contou com a parceria da Fapesp, responsável por 50\% dos recursos, que totalizaram 3 milhões de reais. Este projeto evoluiu para o modelo de inovação aberta. Metade das 120 novas tecnologias que a empresa pesquisou em 2008 foi feita por uma rede de parceiros, que conta com quase 100 universidades e empresas, no Brasil e no exterior, reduzindo o tempo de desenvolvimento de novos produtos, de cinco para dois anos (Mano, 2008).

Os maiores desafios são a continuidade do processo de internacionalização, consolidando a presença na América Latina, e o aprimoramento da relação com as comunidades tradicionais. A empresa deverá, em dois anos, iniciar produção em outros países da região, por empresas terceirizadas. O plano de expansão na Europa e a entrada nos Estados Unidos - o maior mercado de cosméticos e vendas diretas do mundo - foram adiados. Em 15 anos, os negócios no exterior deverão corresponder a $30 \%$ do faturamento (Madureira, 2009).

\subsection{TOTVS S.A.}

A Totvs S.A é uma holding que congrega 21 empresas, incorporadas ao longo de 26 anos. Ela começou como Microsiga, fundada em 1983 como um desdobramento da Siga (Sistema Integrado de Gerência Automática), birô de serviços criado em 1974, cujo objetivo era a automação de procedimentos administrativos, permitindo a integração de processos entre os diversos departamentos de uma empresa. Fruto da visão de Laércio Cosentino, sócio da Siga, que enxergou o futuro papel da microinformática nos sistemas de gestão empresarial (Cosentino, Haberkorn, \& Cícero, 2001), o desafio era introduzir tais sistemas em empresas com controle manual, serviços terceirizados ou com aplicações em mainframe, e esse público-alvo não interessava às grandes multinacionais, como SAP e Oracle.

A Microsiga tornou-se, em pouco tempo, uma das raras empresas brasileiras do setor com padrão internacional. Era líder absoluta no mercado de software de ERP/CRM no segmento low-end (pequenas empresas), com mais de 50\% de participação, e presença crescente nos segmentos de 
médias e grandes. Conhecia as necessidades das empresas, possuía canais de distribuição bem desenvolvidos, produtos em linha com as melhores tecnologias em uso nos Estados Unidos e na Europa, e uma excelente equipe de desenvolvimento de produto.

A estratégia de desenvolvimento de produtos consistia em criar diversas versões e funcionalidades, regularmente atualizadas, para atender à variedade de negócios e ambientes operacionais dos clientes, acompanhando os lançamentos de empresas como Microsoft e Oracle e desenvolvendo soluções específicas (Nascimento, Xavier, Matarossi, \& Lucchesi, 2002). A empresa fazia a implantação, manutenção, treinamento e validação da qualidade do serviço, além de desenvolver softwares de gestão para segmentos específicos, como universidades e empresas de saúde.

Em 1989, a empresa iniciou o projeto de franquias, com as filiais do Rio de Janeiro, Belo Horizonte e Recife, apostando no grande potencial desse tipo de negócio. A experiência com as filiais mostrou que empresas de serviços têm seu patrimônio baseado em bons profissionais, daí a decisão foi crescer com executivos donos do próprio negócio. A quarta franquia foi a de Porto Alegre, de um cliente que havia implantado o Siga. As franquias agregaram valor ao processo operacional da Microsiga que, por outro lado, gerava novas oportunidades de negócios, produtos e serviços para elas (Totvs, 2008).

Em 1996, a Microsiga foi a primeira empresa brasileira de software a obter o certificado ISO 9001. Em 1999, foi lançado o Advanced Protheus Language (ADVPL), que se tornou a base das soluções da empresa. Atualizado periodicamente, colocou a empresa na fronteira do conhecimento em softwares de gestão. Trata-se de um conjunto de funcionalidades, composto por 45 módulos e 3.400 rotinas, que permitem diferentes configurações para os usuários. A empresa acompanha as necessidades dos clientes e consegue incorporá-las às novas versões do sistema. Visitas mensais de manutenção e a estrutura de atendimento aproximam a empresa dos clientes. Em 2001, todas as franquias receberam certificação ISO 9002.

O processo de internacionalização começou em 1997, com a instalação da Microsiga Argentina. A empresa crescia acima de $50 \%$ ao ano, e esse foi o caminho para competir com as empresas internacionais. Em 2003, com a compra de ativos da empresa Sipros, instalou-se a Microsiga México. Em 2007, foi criada a EuroTotvs, em Portugal. Hoje, a empresa tem uma carteira de 400 clientes no exterior, e está presente em 23 países. Mas a receita internacional representa apenas 5\% do faturamento. Já foram mapeadas novas oportunidades de aquisição na América Latina e em países de língua portuguesa.

A independência tecnológica foi definida como objetivo essencial para o crescimento da empresa, em 1993, o que significava evoluir prevendo as tendências dos fabricantes de softwares Revista de Administração e Inovação, São Paulo, v. 7, n. 3, p. 120-149, jul./set. 2010 
básicos. Para alcançá-la, era preciso obter informações antecipadas, aproximar-se das universidades para divulgar os produtos e apresentar ao mercado soluções complementares e inovadoras (Gurovitz, 2005). Se um cliente passa a utilizar uma nova tecnologia, a Totvs cria uma versão do sistema adequada a ela.

Em fevereiro de 2005, a fusão entre a Logocenter e a Microsiga criou a maior empresa latinoamericana de software empresarial - com faturamento de 370 milhões de reais em 2004, 3 mil funcionários diretos e indiretos, 8 mil clientes no Brasil e 300 na América Latina. As duas empresas mantiveram seus principais produtos, ocorrendo a sinergia na área administrativa, no desenvolvimento de novas tecnologias, e nas alianças e novos negócios. Houve uma reorganização societária, ingressando a BNDESAR com 17\% do capital. A Microsiga tornou-se holding, com o novo nome Totvs. Após a fusão, abriu o capital, em 2006, o que possibilitou a compra da concorrente RM Sistemas, atingindo $24 \%$ de participação de mercado, um ponto à frente da SAP e oito à frente da Oracle, tornando-se líder do mercado brasileiro de software empresarial (Vieira, 2006).

Em 2007, a empresa se associou à Quality Software S.A., para o desenvolvimento de um software intermediário (middleware) denominado Ginga TQTVD, que permite a implementação de aplicações interativas para a TV Digital. Com isso, ela se tornou a quinta empresa no mundo a desenvolver middleware e aplicá-lo em suas soluções sistêmicas. As demais são a Microsoft (Dot Net), SAP (NetWeaver), Oracle (Fusion) e IBM (WebSphere) (Cosentino, 2009).

Em 2008, foi adquirida a Datasul, mantendo-se a separação de produtos, uma vez que os clientes são distintos - a Datasul trabalha com médias e grandes empresas. Ao incorporar suas principais concorrentes, a Totvs aumentou sua competitividade e a linha de produtos e serviços, tornando-se líder em todos os segmentos do mercado brasileiro, com 38\% de participação, ultrapassando a SAP (23\%) e a Oracle (18\%) (Namour, 2009).

As despesas com pesquisa e desenvolvimento atingiram $\mathrm{R} \$ 69$ milhões em 2008, representando $10 \%$ da receita líquida. Também em 2008, ocorreu a conversão das principais franquias de distribuição em Franquias Totvs. São 130 no Brasil, 18 internacionais e mais de 600 vendedores. A Totvs foi a primeira empresa aprovada no Novo Mercado da Bovespa e a primeira de TI na Bolsa (Cosentino, 2009).

A Totvs tem 9 mil funcionários (4.500 diretos), uma carteira de 23 mil clientes corporativos, e faturou 845 milhões de reais em 2008. É a maior fornecedora de softwares de gestão empresarial e serviços relacionados no país, segunda na América Latina e oitava no mundo. A criação da Totvs é um caso raro em que se abriu mão de marcas conhecidas em benefício de um processo de integração (Namour, 2009).

Revista de Administração e Inovação, São Paulo, v. 7, n. 3, p. 120-149, jul./set. 2010 
Podem ser consideradas vantagens competitivas da Totvs: seu sistema de distribuição - 226 canais, entre unidades próprias e franquias, que atendem as demandas no Brasil, América Latina e Europa; ênfase na qualificação constante dos colaboradores; tecnologia proprietária e ampla variedade de produtos e soluções; e a força da nova marca, que tem conseguido refletir o prestígio e a reputação herdados das antigas marcas, que se tornaram produtos (Microsiga Protheus, Logix, Datasul e RM).

\subsection{EMBRAER}

Grandes investimentos em educação e em P\&D impulsionaram uma empresa baseada em tecnologias avançadas, em um setor extremamente competitivo, dominado por companhias de países desenvolvidos. A Embraer é uma das maiores empresas aeroespaciais e líder mundial na fabricação de jatos comerciais com até 120 assentos. Em 40 anos de existência, já produziu mais de 5 mil aviões, que operam em 78 países. Projeta, desenvolve, fabrica e vende aeronaves para os segmentos de aviação comercial (67\% da receita), aviação executiva (14\%) e defesa (8\%). Também fornece suporte e serviços de pós-venda a clientes em todo o mundo (9\% da receita). São mais de 21 mil empregados no Brasil e 1.960 nas fábricas da China e Portugal. Em 2008, foi a terceira maior exportadora brasileira, depois da Petrobrás e Vale, com US\$ 4,7 bilhões, que correspondem a 96\% de sua receita (Empresa Brasileira de Aeronáutica S. A. [EMBRAER], 2008).

No exterior, possui sete escritórios comerciais e centros de serviço e venda de peças de reposição, localizados nos Estados Unidos, na França, China e em Cingapura. Desde dezembro de 2002, possui uma fábrica na China (Harbin Embraer Aircraft Industry - HEAI) para a montagem, venda e suporte pós-vendas para os aviões da família ERJ 135/140/145, em associação com a estatal AVIC, na qual possui $51 \%$ de participação. A fábrica impediu a perda de mercado, após o governo decidir taxar a importação de jatos regionais.

A Embraer também controla 65\% do capital da Ogma - Indústria Aeronáutica de Portugal S.A., uma empresa de manutenção e produção aeronáutica, em Portugal. E vai implantar três novas unidades industriais - duas na cidade de Évora, Portugal, e uma nos Estados Unidos, onde fabricará jatos executivos. Os investimentos nas três fábricas são de US\$ 198 milhões. As fábricas em Portugal vão gerar 1.500 empregos e será a maior operação fora do Brasil.

A Embraer foi fundada em 1969, como empresa de economia mista, de capital aberto, vinculada ao Ministério da Aeronáutica, da qual o governo possuía 51\% do capital votante. Sua missão era implantar a indústria aeronáutica no país, desenvolvendo capacidade tecnológica autônoma. O Centro Técnico Aeroespacial (CTA), constituído em 1945, e o Instituto Tecnológico da Aeronáutica (ITA), 
em 1947, foram criados para desenvolver massa crítica de cientistas voltados ao desenvolvimento e/ou absorção da tecnologia aeronáutica, e a criação da empresa foi uma consequência natural. Desde o início, contou com forte apoio do Estado, por meio de incentivos fiscais, políticas de compra, contratos de licenciamento de tecnologia com empresas estrangeiras, formação de recursos humanos de alto nível, treinamento de engenheiros brasileiros no exterior, vinda de professores e técnicos estrangeiros, e fomento para a execução de pesquisa básica e aplicada (R. Bernardes, 2000). Sempre se destacou pela importância estratégica conferida aos programas de qualificação e formação profissional de seus funcionários.

O objetivo da Embraer era a autonomia tecnológica, incluindo a compreensão do ciclo completo da fabricação de aviões, através do seu desenvolvimento e produção. A prioridade foi dada à inovação tecnológica, com pouca atenção aos custos de produção e à busca de alternativas de financiamento. Mas o fim da Guerra Fria resultou na redução de gastos com defesa, que coincidiu com uma queda nas compras de novos aviões pelas companhias aéreas, atingindo especialmente os turboélices, principal produto da Embraer (Sull \& Escobari, 2004). Em dezembro de 1994, após atravessar grave crise econômico-financeira, a empresa foi privatizada, modificando o modelo de gestão, ao aproveitar as competências tecnológicas, porém orientando-as para resultados (Ghoshal \& Tanure, 2004). Em 1997, os jatos regionais respondiam por $60 \%$ das vendas da Embraer, tornando-a novamente lucrativa.

A Embraer é responsável pela concepção do projeto, e abriu mão de se capacitar para a construção de motores, componentes, peças e aviônica, privilegiando o domínio tecnológico nas áreas de aerodinâmica, fuselagem e integração de projeto. Para Chagas Junior e Cabral (2004), ela é uma firma integradora de sistemas, responsável pela coordenação da inovação e produção, tanto de suas atividades como de uma rede de fornecedores de equipamentos, componentes e conhecimentos especializados. Aperfeiçoou detalhes na tecnologia de aviões consagrada, produzindo aeronaves mais baratas, eficientes e competitivas. Pretende levar para a aviação executiva os conceitos de baixo custo e alta segurança, usados nos jatos comerciais.

A empresa investiu 480 milhões de reais em $P \& D$, produtividade e capacitação industrial em 2008, Há vários projetos de novas tecnologias, especialmente na utilização de materiais compostos em estruturas primárias (asas e fuselagem). Nos últimos quatro anos, o nível de disponibilidade técnica dos aviões $170 / 190$ foi de $99,8 \%$, o que significa que apenas $0,2 \%$ dos voos tiveram que ser cancelados por algum problema técnico.

Uma inovação organizacional pioneira foi o conceito de parcerias de risco para o desenvolvimento tecnológico, entre a Embraer e seus fornecedores, muitos internacionais, que permite rapidez na conclusão dos projetos, fator vital de sucesso (Damiani, 2001). Empresas fornecedoras 
participam financeiramente do programa, responsabilizando-se pela fabricação de partes do avião. Em troca, a Embraer lhes transfere determinadas tecnologias, além de uma participação nos resultados provenientes das vendas. Isso começou com o projeto do ERJ 145 e se estendeu para a nova família ERJ 170/190.

\subsection{MARCOPOLO S.A.}

Os fabricantes de ônibus dividem-se em dois grupos - empresas integradas, que produzem o chassi, o motor e a carroceria - e as que fabricam exclusivamente a carroceria, caso da Marcopolo, que recebe o chassi e o motor de seus clientes - as empresas transportadoras. A Marcopolo produz internamente cerca de $80 \%$ dos componentes e acessórios de que precisa para montar um ônibus, como poltronas, janelas, painéis e bagageiros.

No segmento de ônibus rodoviários, os clientes valorizam elementos de conforto, como poltronas macias, ar-condicionado e baixo ruído interno, com produtos de maior valor agregado e preços mais elevados. No segmento urbano, as exigências são menores, os produtos são padronizados, e a concorrência se dá por causa do preço (Paiva \& Hexsel, 2003). Tecnologicamente, a indústria é considerada tradicional - as mudanças são incrementais, em materiais e processos de fabricação. No Brasil, houve muitas inovações organizacionais, com a utilização de técnicas gerenciais de trabalho em equipes, programas de qualidade total, certificação ISO 9000, just in time, etc., que melhoraram a organização do trabalho e o relacionamento clientes-fornecedores. Mas há oportunidades para a inovação de produtos e processos, em que a Marcopolo se destaca em nível mundial.

Fundada em 1949, é líder no setor, com mais de $40 \%$ da produção brasileira, e exporta para mais de 80 países. É uma das principais fabricantes internacionais, contribuindo com $6 \%$ a $7 \%$ da produção mundial. Em 2008, produziu 21 mil ônibus (deste total, 16.365 foram produzidos no Brasil e 5.446 no exterior) e possuía 12.880 funcionários, sendo 2.600 no exterior. A receita líquida foi de 2,4 bilhões de reais (Marcopolo, 2008).

A inovação tem um papel de destaque na Marcopolo, no lançamento de produtos. Foi a primeira empresa a montar carrocerias em estrutura de aço, substituindo a madeira, em 1952. Em 1984, lançou o conceito de ônibus mais alto que o padrão da época, o ônibus de piso e meio, conhecido como Lowdriver, no qual o motorista fica num plano mais baixo. Em 1996 lançou o ônibus de dois andares, o Double-decker, inicialmente para o mercado argentino (Cardoso, 2000). Não há outro fabricante com linhas de ônibus tão diversificadas - de míni e microônibus até os de dois andares ou biarticulados, ônibus rodoviários, normais e adaptados. Ela fabrica ônibus conversíveis para os peregrinos 
muçulmanos que viajam a Meca: além de ser conversível, o modelo tem outras peculiaridades, como calha para esgotar a água da chuva e estofamentos resistentes à umidade. Também fabrica ônibus com divisórias para separar homens e mulheres, e modelos resistentes a temperaturas supergeladas, para trafegar na Sibéria. Pedidos assim fazem da Marcopolo a maior fabricante mundial de ônibus sob encomenda, customizando o produto para o cliente, que escolhe o chassi preferido. Este é o diferencial competitivo da Marcopolo. São 3 milhões de combinações entre diferentes itens, como poltronas, local da direção e tamanhos de janelas (Adeodato, 2009).

Após três anos de desenvolvimento e 30 milhões de reais investidos, foi lançada em 2009 a Geração 7 de ônibus rodoviários. Os veículos consomem 10\% menos combustível e têm maior capacidade de transporte de passageiros, e foram definidos a partir de pesquisas com usuários do Brasil e exterior, gerando 35 pedidos de patentes, de produtos e de processos (Ferreira, 2009).

Os ônibus são, em geral, exportados em partes, e a montagem é feita pelas unidades operacionais no exterior, o que reduz significativamente o custo do veículo, além de contornar barreiras sobre a importação de produtos acabados, ao utilizar mão de obra e alguns serviços do país-alvo. Podem ser carrocerias semidesmontadas (partially knocked down, PKD) ou totalmente desmontadas (CKD, completely knocked down) (E. S. Bernardes, 2000).

A Marcopolo enfatizou inicialmente o mercado interno, com a exportação servindo apenas para diminuir a ociosidade das fábricas, em momentos de menor venda. Apesar de o mercado brasileiro ser um dos maiores do mundo, praticamente inexistindo o transporte ferroviário de passageiros, as oscilações e a forte concorrência não permitem que a empresa dependa exclusivamente dele. A partir das capacidades acumuladas, competir com as empresas líderes no mercado mundial passou a ser o objetivo central das ações estratégicas da Marcopolo (Bisi, 2005). Ela possui quatro fábricas no país e dez no exterior: Argentina (33\% da Metalpar), Colômbia, México, Portugal, África do Sul, Rússia (duas fábricas - atualmente uma foi fechada, e a outra trabalha em ritmo reduzido), Índia (duas fábricas) e China (fábrica de componentes, aberta em 2008). Uma nova fábrica está sendo construída no Egito, em parceria com o grupo GB Buses, para atender o norte da África e o Oriente.

O controle dos ativos tecnológicos influenciou a estratégia de montar fábricas no exterior, em vez de licenciar a tecnologia. Algumas unidades são operadas em parceria com fabricantes de chassis, o que ajuda o desenvolvimento tecnológico. A Marcopolo possui parceria com o grupo sueco Scania para produzir ônibus na África do Sul, com a Volvo na Colômbia, com a Mercedes-Benz no México. Essas alianças estratégicas seguem uma tendência mundial, em que as montadoras dividem responsabilidades com os parceiros. 
A planta de Portugal, a primeira no exterior, instalada em 1991, funcionava como posto avançado de observação, colhendo informações sobre os avanços tecnológicos na indústria europeia. A opção por Portugal deveu-se ao custo da mão de obra e ao idioma. Dali, foi possível o acesso ao sofisticado mercado europeu e o intercâmbio tecnológico entre as várias unidades da empresa, além da proximidade com fornecedores, clientes e concorrentes. O nível de atividades técnicas é superior ao das outras plantas, por causa das exigências muito maiores do mercado, em termos de componentes e produto final - normas de segurança mais rígidas, exigência de tecidos incombustíveis, vidros mais seguros e componentes diferenciados. Por isso, compram-se componentes localmente, em vez de mandá-los do Brasil. As atividades de desenvolvimento de produtos e processos são feitas no Brasil, mas a fábrica de Coimbra pode modificá-los para as condições locais, responsabilizando-se pela qualidade do produto final. Entretanto, dada sua baixa produção (cerca de 160 unidades/ano), a fábrica foi fechada em agosto de 2009, e os clientes europeus serão atendidos pela fábrica egípcia, que deverá entrar em operação em janeiro de 2010.

As demais plantas da empresa foram localizadas em função do mercado. Os maiores clientes de ônibus, principalmente urbanos, são países em desenvolvimento, daí as exportações serem dirigidas predominantemente para América Latina, África e Oriente Médio.

Como parte do processo de internacionalização, a Marcopolo optou pelo modelo de suprimento denominado de global sourcing, cujo objetivo é produzir peças e componentes onde o custo for mais baixo, desde que mantida a qualidade reconhecida de seus produtos. Hoje, há fornecedores em todas as regiões onde ela opera, o que propicia à empresa maior flexibilidade de produção, independentemente da volatilidade cambial. Mesmo que a taxa de câmbio volte a tornar mais vantajosa a exportação de peças e componentes do Brasil para suas coligadas no exterior, é de vital importância contar com parceiros locais que forneçam, no mínimo, $20 \%$ das necessidades em cada região.

\section{ANÁLISE E DISCUSSÃO DOS RESULTADOS}

Neste item, a trajetória das empresas estudadas é cotejada com as principais teorias de negócios internacionais - teorias comportamentais e teorias econômicas - que explicam as decisões tomadas pelas empresas com vistas à internacionalização. São analisadas as motivações que levaram as empresas a se expandir no mercado internacional, e também as estratégias tecnológicas adotadas.

$\mathrm{Na}$ área de Administração, o processo de internacionalização de empresas tem sido mais estudado à luz das teorias comportamentais, que explicam o comprometimento de recursos em novos 
mercados de forma gradual, partindo da exportação até a produção e desenvolvimento no país de destino. Porém, quando a capacidade tecnológica sustenta a conquista de novos mercados, as teorias econômicas oferecem melhor explicação, enfatizando os custos de transação entre as alternativas de repassar o conhecimento para empresas locais, através de licenciamento, ou internalizar a produção, aproveitando a vantagem competitiva resultante (Dunning, 1988). A instalação de fábricas em outros países, que passam a gerar inovações a partir de conhecimento específico, atendendo às necessidades dos clientes locais, é a alternativa preferencial. Foi o que ocorreu com a Marcopolo: mesmo sendo uma empresa muito inovadora, a parceria com fabricantes no México, Colômbia e na África do Sul contribuiu para manter sua posição competitiva. O mesmo se aplica à Totvs, na qual as franquias agregam novo conhecimento, derivado de suas experiências locais.

Para as teorias econômicas, a compra ou a associação com empresas locais permite obter as vantagens proprietárias da empresa adquirida (tecnologia e conhecimento do mercado) e reduzir os custos de transação da entrada no novo mercado (Dunning, 1988). A posse de tecnologias inovadoras garante a competitividade em mercados mais desenvolvidos - a Sabó possui mais de 140 patentes - e é essencial para manter a posição alcançada.

A aquisição da Kaco constituiu uma aliança tecnológica, visando complementar a capacidade própria da Sabó e aproximá-la dos clientes internacionais, além de evitar a compra da Kaco por um concorrente, o que reduziria o espaço de atuação da Sabó junto às montadoras europeias. A opção pela Alemanha deve-se ao fato de este país ser um centro de excelência mundial em plásticos e elastômeros. Esta foi tipicamente uma motivação relacionada a strategic asset seeking (Dunning, 1994), enquanto a fábrica na Hungria representou efficiency seeking, e a entrada na Argentina, market seeking. A fábrica americana também reflete uma busca por ativos estratégicos - já havia um escritório técnico/comercial desde 1994 e um laboratório de desenvolvimento de produtos para a GM e a Delphi.

Como as teorias comportamentais não explicam adequadamente a trajetória da Sabó, o conceito de distância psíquica (Johanson \& Vahlne, 1977) se aplica apenas em parte. A aquisição de fábricas ocorreu primeiramente na Argentina (em 1992), logo em seguida na Europa (1993) e apenas em 2007 nos Estados Unidos. Apesar de a Hungria ser a terra natal do fundador da empresa, a firma se instalou naquele país para seguir a Audi.

Quanto à tipologia de estratégias (Freeman \& Soete, 2008), Sabó, Embraer, Natura e Marcopolo adotam estratégias tecnológicas ofensivas, buscando a liderança perante os concorrentes por meio do desenvolvimento de novos produtos. A excelência técnica dos produtos é fundamental, ao lado de certa agressividade mercadológica. Isto inclui vínculos com a comunidade científica, bem como forte atividade interna de $\mathrm{P} \& \mathrm{D}$, com profissionais qualificados, e a obtenção de patentes como proteção a 
sua atividade inovadora. A Totvs seguiu uma estratégia oportunista, ao perceber o potencial de utilização de softwares de gestão para pequenas empresas, nicho de mercado negligenciado pelos grandes fabricantes.

A loja da Natura em Paris tem funcionado como um posto avançado de observação de tendências mundiais (market seeking e strategic asset seeking). O lançamento de produtos é fundamental para manter sua posição no mercado, entretanto, a vantagem competitiva resulta, principalmente, da força da marca, da penetração no mercado, das vendas por relacionamento, que resultam em fidelidade, tanto dos consumidores quanto das consultoras (Pommez, 2004). A empresa já avançou em vários estágios do processo de internacionalização, de acordo com a teoria comportamental. Ela apresenta forte atividade exportadora, a presença de escritórios comerciais, centros de distribuição, o modelo bem-sucedido de venda direta por meio de consultoras, na América Latina, e a experiência de lojas próprias na França e em alguns países da América Latina. Mas as teorias econômicas também explicam seu processo de internacionalização. Ao investir sozinha, em vez de associar-se a empresas locais, ela objetiva resguardar seu patrimônio tecnológico e seu conhecimento sobre a biodiversidade brasileira, que constitui uma vantagem de origem.

Dada a especificidade do setor, a Embraer já nasceu internacionalizada, com clientes globais. Ao atuar numa indústria global de alta tecnologia, a forte capacitação e o domínio tecnológico das diferentes fases de montagem dos aviões são imprescindíveis, especialmente se considerarmos as parcerias de risco internacionais utilizadas para o desenvolvimento de seus aviões ERJ 145 e ERJ 170/190 (strategic asset seeking). Mas ela também deve sua vantagem competitiva à escolha de um nicho de mercado (estratégia tecnológica oportunista) não atendido pelas grandes empresas aéreas jatos regionais de 30 a 100 assentos. No caso da indústria aeronáutica, não é comum a instalação de subsidiárias no exterior, mas a construção de uma fábrica na China se justifica pela grande distância cultural entre os dois países, tornando a empresa mais conhecida no mercado asiático, o que poderá gerar novas oportunidades de negócios (market seeking). As associações com a Ogma, em Portugal, com a Lockheed, nos Estados Unidos e com a Dassault, na França, permitem obter as vantagens proprietárias dessas empresas, reduzindo os custos de transação da entrada no novo mercado.

O desenvolvimento de novos produtos é essencial para a Totvs, mas a vantagem competitiva vem do modelo de negócios (franquias), que permite um atendimento muito próximo aos clientes, com soluções rápidas (efficiency seeking). As franquias agregam valor ao processo operacional da Totvs que, por sua vez, gera novas oportunidades de negócios, produtos e serviços para as franquias. A empresa também percebeu a oportunidade junto às pequenas empresas, para as quais os softwares de 
gestão das grandes firmas mundiais são inadequados, pela alta complexidade e sofisticação, que vão além das necessidades dessas empresas, o que os torna, também, muito caros.

A Marcopolo é inovadora em produtos e processos, mas seu grande diferencial competitivo é a capacidade de atendimento aos clientes, com a customização de produtos. A experiência de atender o mercado brasileiro, no qual o uso de ônibus rodoviários e urbanos é intenso, e exige diferentes modelos e adaptações, preparou a empresa para o mercado internacional, especialmente em países em desenvolvimento que utilizam intensamente o transporte público (market seeking). O desenvolvimento e a produção no exterior, em parceria com empresas estrangeiras, refletem a motivação de busca de eficiência (Dunning, 1994). O Quadro abaixo resume a análise das cinco empresas estudadas.

\begin{tabular}{|c|c|c|c|c|}
\hline Empresas & Setor & $\begin{array}{c}\text { Estratégia de } \\
\text { crescimento global }\end{array}$ & $\begin{array}{l}\text { Vantagem } \\
\text { competitiva }\end{array}$ & $\begin{array}{l}\text { Contribuição da inovação } \\
\text { tecnológica para a VC }\end{array}$ \\
\hline SABÓ & autopeças & $\begin{array}{l}\text { Aquisições e novas } \\
\text { fábricas }\end{array}$ & $\begin{array}{l}\text { produtos inovadores; } \\
\text { patentes }\end{array}$ & $\begin{array}{l}\text { fundamental para a competição } \\
\text { global }\end{array}$ \\
\hline NATURA & $\begin{array}{l}\text { higiene e } \\
\text { cosméticos }\end{array}$ & $\begin{array}{l}\text { Venda direta por } \\
\text { meio de consultoras }\end{array}$ & $\begin{array}{l}\text { canais de distribuição; } \\
\text { relacionamento c/cliente }\end{array}$ & necessária para competir \\
\hline EMBRAER & aeronáutico & $\begin{array}{l}\text { Parceria com } \\
\text { fornecedores no } \\
\text { desenvolvimento }\end{array}$ & $\begin{array}{l}\text { Integração de sistemas } \\
+ \text { nicho de mercado }\end{array}$ & $\begin{array}{l}\text { fundamental para participar do } \\
\text { setor }\end{array}$ \\
\hline TOTVS & software & Franquias & $\begin{array}{l}\text { customização; nicho de } \\
\text { mercado; atendimento } \\
\text { ao cliente }\end{array}$ & necessária para competir \\
\hline MARCOPOLO & $\begin{array}{l}\text { carrocerias de } \\
\text { ônibus }\end{array}$ & $\begin{array}{l}\text { Fábricas próprias ou } \\
\text { parcerias }\end{array}$ & $\begin{array}{l}\text { customização; } \\
\text { atendimento ao cliente }\end{array}$ & necessária para competir \\
\hline
\end{tabular}

Quadro 1- Contribuição da inovação tecnológica para o sucesso no mercado internacional

Fonte: Elaborado pela autora

\section{CONCLUSÕES}

Optar pela internacionalização é uma decisão estratégica. Exportar é o primeiro estágio, e às vezes o único, pois a empresa quer apenas se livrar de excedentes de produção, sem realmente ter como objetivo uma forte inserção internacional. Ir além da exportação, percorrendo os vários estágios desse processo, exige um planejamento de longo prazo. 
A exposição a novos mercados e à maior competição estimula e, em alguns casos, exige a maior qualidade de bens e serviços. De modo geral, as capacidades inovadoras das empresas brasileiras foram desenvolvidas internamente ou a partir de acordos de licenciamento de tecnologia com empresas estrangeiras e aperfeiçoadas por esforço próprio ou em parcerias com universidades e institutos de pesquisa, em um intenso processo de aprendizagem.

Os cinco estudos de caso apresentados, sobre empresas brasileiras de diferentes setores, evidenciam a relevância da inovação tecnológica para a construção da vantagem competitiva. Todas começaram exportando (Totvs é a exceção, dada a sua atividade e seu modelo de negócio), e mantêm as exportações, tanto a partir do Brasil como dos países onde se instalaram. Porém, sua expansão, por meio de escritórios técnicos e comerciais, seguida pelo estabelecimento de operações industriais, só foi possível dada a competitividade de seus produtos em escala regional ou global. A posição de liderança alcançada no Brasil estimulou as empresas a testar sua vantagem competitiva em outros mercados.

Experiências de vários países relatadas por organismos internacionais, como Organisation for Economic Co-Operation and Development (OCDE, 2004) e UNCTAD (2004), mostram que políticas de apoio à internacionalização de empresas devem se concentrar no aumento da capacidade de competição, com a qualificação de recursos humanos em todos os níveis e a capacitação tecnológica.

\section{REFERÊNCIAS}

Adeodato, S. (2009, 19 de agosto). Emergentes aquecem a corrida tecnológica global. Valor Econômico, p. 7-8I, 19.

Arbix, G., Salerno, M. S., \& De Negri, J. A. (2005). O impacto da internacionalização com foco na inovação tecnológica sobre as exportações das firmas brasileiras. Dados, 48(2), 395-442.

Associação Brasileira da Indústria de Higiene Pessoal, Perfumaria e Cosméticos. (2008). Pesquisa geral no site. Recuperado em 23 outubro, 2008, de http://www.abihpec.org.br.

Barney, J. B. (1991). Firm resources and sustained competitive advantage. Journal of Management, 17(1), 99-120.

Bernardes, E. S. (2000). Configuração internacional da atividade produtiva: estudo de caso em uma montadora de carrocerias para ônibus. 2000. Dissertação de Mestrado, Escola de Administração, Universidade Federal do Rio Grande do Sul, Porto Alegre.

Bernardes, R. (2000). O caso Embraer - privatização e transformação da gestão empresarial: dos imperativos tecnológicos à focalização no mercado (Cadernos de Gestão Tecnológica, n. 46). São Paulo: PGT/USP. 
Bisi, R. A. (2005). A influência da inovação na competitividade nacional e global da empresa Marcopolo S.A. Revista Fórum de Líderes, 8(12), 102-103.

Cardoso, M. A. (2000). Estratégia tecnológica e competitividade: o caso da Marcopolo. Dissertação de Mestrado, Escola de Administração, Universidade Federal do Rio Grande do Sul, Porto Alegre.

Castro, J. A. (2009, 16 de fevereiro). A pauta obsoleta das exportações brasileiras. (Entrevista a PROTEC). Notícias PROTEC, p. 1.

Chagas Junior, M. F., \& Cabral, A. S. (2004). Firmas integradoras de sistemas, suas capacitações e fontes de tecnologia: o caso da Embraer [CD-ROM]. Anais do Simpósio de Gestão da Inovação Tecnológica, 23. São Paulo: PGT/USP.

Chudnovsky, D., \& López, A. (2000). A third wave of FDI from developing countries: Latin America TNCs in the 1990s. Transnational Corporations, 9(2), 31-73.

Cosentino, L. (2009). Tudo para todos. (Entrevista concedida a Sandro Magaldi). HSM Management, $75,26-35$.

Cosentino, L., Haberkorn, E., \& Cícero, F. (2001). Genoma empresarial: incluindo história e trajetória Microsiga. São Paulo: Gente.

Costa, M. (2009, 03 de junho). O plano deu certo. Exame, 944, p. 1.

Damiani, J. H. S. (2001). A nova face da gerência de produtos - o projeto do avião ERJ-170 na Embraer. Revista da ESPM, 8(2), 89-95.

Dunning, J. H. (2001). The eclectic (OLI) paradigm of international production: past, present and future. International Journal of the Economics of Business, 8(2), 173-190.

Dunning, J. H. (1994). Multinational enterprises and the globalization of innovatory capacity. Research Policy, 23(1), 67-88.

Dunning, J. H. (1988). The eclectic paradigm of international production: a restatement and some possible extensions. Journal of International Business Studies, 19(1), 1-31.

Empresa Brasileira de Aeronáutica S. A. (2008). Relatório anual 2008. São Paulo: Autor.

Ferraz, E. (2002, 15 de julho). Movendo as peças: com cinco unidades na Europa, a Sabó, maior fabricante nacional de autopeças, tenta ganhar o mercado americano e se manter independente. Exame, 770, p. 1.

Ferreira, R. G. (2009). O ônibus global da Marcopolo. Isto É Dinheiro, 12(619), 64-65. 
Ferro, A. F. P., \& Bonacelli, M. B. M. (2006). Redes de inovação e parcerias estratégicas: promovendo o uso sustentável da biodiversidade brasileira [CD-ROM]. Anais do Simpósio de Gestão da Inovação Tecnológica, 24. Rio de Janeiro: ANPAD.

Festinger, L., \& Katz, D. (1966). Research methods in the behavior sciences. New York: Holt, Rinehart and Winston.

Freeman, C., \& Soete, L. (2008). A economia da inovação industrial (A. L. S. Campos \& J. O. P. Costa, Trad.). Campinas: Unicamp.

Ganem, C., \& Santos, E. M. (Coords.). (2006). Brasil inovador: o desafio empreendedor - 40 histórias de sucesso de empresas que investem em inovação. Brasília: IEL-NC.

Ghoshal, S., \& Tanure, B. (2004). Estratégia e gestão empresarial. Rio de Janeiro: Elsevier.

Gil, A. C. (2002). Como elaborar projetos de pesquisa (4a ed.). São Paulo: Atlas.

Gomes, C. M., \& Kruglianskas, I. (2005). Gestão de fontes externas de inovação: estudo de caso em empresas brasileiras [CD-ROM]. Memorias do Seminário Latino-Iberoamericano de Gestión Tecnológica, 11. Buenos Aires: ALTEC.

Gurovitz, H. (2005, 16 de fevereiro). Fusão no software. EXAME, 836, p. 1.

Iglesias, R. M., \& Veiga, P. M. (2002). Promoção de exportações via internacionalização das firmas de capital brasileiro. In A. C. Pinheiro, R. Markwald, \& L. V. Pereira (Orgs.), O desafio das exportações (pp. 368-446). Rio de Janeiro: BNDES.

Johanson, J., \& Vahlne, J. E. (1977). The internationalization process of the firm: a model of knowledge development and increasing foreign market commitments. Journal of International Business Studies, 8(1), 23-32.

Lacerda, A. C. (2004). Globalização e investimento estrangeiro no Brasil. São Paulo: Saraiva.

Levy, L. F. (2002). As multinacionais brasileiras. In L. F. Levy. O novo Brasil (pp. 173-188). São Paulo: Gazeta Mercantil.

Madureira, D. (2009, 20 de novembro). No exterior, Natura põe o pé no chão e adota novo plano. Valor Econômico, p. B1.

Mano, C. (2008, 12 de junho). A inovação sem fronteiras. EXAME, 920, p. 1.

Marcopolo S.A. Relatório anual 2008. Caxias do Sul: Autor. 
Minda, A. (2008). The strategies of multilatinas: from the quest for regional leadership to the myth of the global corporation. Cahiers $d u$ GRES, 8, 1-27.

Namour, R. (2009). O mestre das fusões. Isto É Dinheiro, 12(621), 1-3.

Narula, R., \& Zanfei, A. (2005). Globalization of innovation: the role of multinational enterprises. In J. Fagerberg, D. C. Mowery, \& R. R. Nelson (Eds.), The Oxford handbook of innovation (pp. 318346). New York: Oxford University Press.

Nascimento, P. T. S., Xavier, W., Matarossi, O., \& Lucchesi, R. N. (2002). O desenvolvimento de software: o caso Microsiga S.A. [CD-ROM]. Anais do Congresso Coppead de Administração, 9. Rio de Janeiro: COPPEAD/UFRJ.

Natura. (2008). Relatório anual Natura 2008. São Paulo: Autor.

Natura. (2007). Relatório anual Natura 2007. São Paulo: Autor.

Nelson, R. R. (2006). As fontes do crescimento econômico. Campinas: Unicamp.

Organisation for Economic Co-Operation and Development. (2004). Science, technology and industry outlook. Paris: Autor.

Paiva, E. L., \& Hexsel, A. E. (2003). A busca de internacionalização: uma análise baseada na área de operações [CD-ROM]. Anais do Encontro da Associação Nacional de Pós-Graduação e Pesquisa em Administração, 27. Rio de Janeiro: ANPAD.

Pommez, P. (2004). Mesa-redonda "O desafio de gerar valor com a inovação". Harvard Business Review Brasil, 82(8), 28-42.

Porter, M. E. (1993). A vantagem competitiva das nações. Rio de Janeiro: Campus.

Rocha, A. (2001). Por que as empresas não se internacionalizam? Rio de Janeiro: COPPEAD/UFRJ.

Schumpeter, J. A. (1985). A teoria do desenvolvimento econômico (2a ed.). São Paulo: Abril Cultural.

Stal, E. (2005). Multinacionais brasileiras: o papel da tecnologia na conquista do mercado externo. Revista de Ciências da Administração, 7(14), 227-247.

Sull, D. N., \& Escobari, M. E. (2004). Sucesso made in Brasil: os segredos das empresas brasileiras que dão certo. Rio de Janeiro: Elsevier.

Tavares, M., \& Ferraz, J. C. (2007). Translatinas: quem são, por onde avançam e que desafios enfrentam? In A. Fleury \& M. T. L. Fleury (Orgs.), Internacionalização e os países emergentes (pp. 120-141). São Paulo: Atlas. 
Teece, D. J., Pisano, G., \& Shuen, A. (1997). Dynamic capabilities and strategic management. Strategic Management Journal, 18(7), 509-533.

Tidd, J., Bessant, J., \& Pavitt, K. (2005). Managing innovation: integrating technological, market and organizational change (3rd ed.). Chichester: John Wiley \& Sons.

Tigre, P. B. (2006). Gestão da inovação: a economia da tecnologia no Brasil. Rio de Janeiro: Campus.

Tigre, P. B. (2002). Política tecnológica na promoção de exportações. In A. C. Pinheiro, R. Markwald, \& L. V. Pereira (Orgs.), O desafio das exportações (pp. 245-282). Rio de Janeiro: BNDES.

TOTVS. Relatório anual 2008. São Paulo: Autor.

United Nations Conference on Trade and Development. (2004). Prospects for foreign direct investment and the strategies of transnational corporations, 2004-2007. New York: Author.

Vieira, E. (2006, 20 de abril). Maior que as múltis. ÉPOCA, 414, p. 1.

\title{
INTERNATIONALIZATION OF BRAZILIAN COMPANIES AND THE ROLE OF INNOVATION IN CONSTRUCTION OF COMPETITIVE ADVANTAGE
}

\begin{abstract}
Many companies from emerging countries are afraid to explore international market due to the distance between global companies and their local technological patterns. In general, they seek technological development by copying, adapting and upgrading exogenous solutions, but a growing number of firms in these countries are standing out in the global scenario, with product and process innovations for foreign markets. Internationalization through direct investment may be the only option for firms that face global competition based on technological innovation. This paper describes the motivations and internationalization trajectories of five Brazilian companies in different industries Sabó (autoparts), Natura (hygiene and cosmetics), Totvs (software), Embraer (airplanes) and Marcopolo (bus bodies) - highlighting the role of technological innovation for their international competitiveness.
\end{abstract}

Keywords: Technological innovation; Emerging countries; Internationalization; Competitiveness.

Data do recebimento do artigo: 05/07/2010

Data do aceite de publicação: 25/09/2010

Revista de Administração e Inovação, São Paulo, v. 7, n. 3, p. 120-149, jul./set. 2010 